\title{
PREVALENCE OF ORAL HABITS AMONG A GROUP OF EGYPTIAN SCHOOL CHILDREN, AND THEIR KNOWLEDGE REGARDING ITS BAD EFFECT ON ORAL HEALTH
}

\author{
Nadia M. Farrag* and Salwa M. Awad ${ }^{* *}$
}

\begin{abstract}
Objective: To provide information regarding the prevalence of oral habits among Egyptian group of 6-12 years old school children in Dakahlya governorate, with relation to their age and sex. Moreover, to record the children knowledge regarding the bad effect of practicing habits on their oral health.

Study design: This cross-sectional study was conducted through a survey questionnaire and clinical examination of 2274 children (1106 males and 1168 females) of age group 6 to 12 years old using multistage stratified cluster random sampling design. This was further sub-divided into two age groups: Group 1 (6-<9 years) and Group 2 (9-12years). Both rural and urban areas of Dakahlya governorate were included. Habits assessed were digit sucking, mouth breathing, tongue thrusting, bruxism, lip/cheek biting, and nail biting. Chi-square test was used to compare the prevalence of oral habits among different sexes and ages at $5 \%$ level of significance.
\end{abstract}

Results: Prevalence of oral habits in Dakahlya school children was found to be $29.1 \%$. Nail biting was found as the commonest habit $(9.7 \%)$ followed by digit sucking $(6.1 \%)$,mouth breathing $(4.6 \%)$, tongue thrusting $(3.4 \%)$ and bruxism(3.1\%). lip/cheek biting was found as the least common habit and seen in only $2.2 \%$ of children . Digit sucking, mouth breathing and tongue thrusting were highly prevalent among Group 1 (6-<9 years) children. However nail biting, bruxism, and lip/cheek biting were higher in Group 2 (9-12 years) cases. There were no statistical significant differences between boys and girls for the prevalence of oral habits $(26 \% \mathrm{vs} 32 \%)$. However, for the specific habit types there was a sex difference. Children awareness by the ill effect of oral habits on their oral health were found in $46.83 \%$, while $53.17 \%$ were not with age and sex differences.

Conclusions: The data revealed that $29.1 \%$ of children had oral habits. This highlights the importance of identifying children who are in need of preventive orthodontic treatment to avoid occurrence of malocclusion.

KEY WORDS: Oral habits, Egyptian school children, Knowledge, Bad effect

\footnotetext{
* Professor of Pediatric Dentistry, Mansoura University, Egypt.

** Associate Professor of Pediatric Dentistry, Mansoura University, Egypt.
} 


\section{INTRODUCTION}

The World Health Organization (WHO) defines health as a state of complete physical, social and mental well-being. ${ }^{1}$ Oral health is an important part of general health and well-being and is more important for the general health of those with oral or craniofacial problems. ${ }^{2}$

Deleterious oral habits are the common problem of pediatricians which affects the quality of life. Oral habits are repetitive behavior in the oral cavity that result in loss of tooth structure and they include digit sucking, pacifier sucking, lip sucking and biting, nail-biting, bruxism, self injurious habits, mouth breathing and tongue thrusting. Their effect is dependent on the nature, onset and duration of habits. ${ }^{3}$

Nonnutritive sucking behaviors (digit sucking) are considered normal in infants and young children and usually are associated with their need to satisfy the urge for contact and security but disappears between the ages of 1 and $3 \frac{1}{2}$ years. ${ }^{4}$ But persistent nonnutritive sucking habits may result in longterm problems and can affect the stomatognathic system, leading to an imbalance between external and internal muscle forces. ${ }^{5}$ Digit sucking and nail biting can damage the structure of the mouth and can easily allow the spread of infectious diseases. In a study in Turkey, in 2007, the authors confirmed statistically significant difference in the prevalence of Escherichia coli and Enterobacteria among children with such oral habits in relation to children without such habits. ${ }^{6}$

Other deleterious oral habits include bruxism which is the habitual nonfunctional forceful contact between occlusal tooth surfaces and can occur due to emotional stress. ${ }^{7}$ It causes dental attrition, headaches, temporomandibular joint dysfunction and soreness of the masticatory muscles. Tongue thrusting, an abnormal tongue position and deviation from the normal swallowing pattern, and mouth breathing may be associated with anterior open bite, abnormal speech and anterior protrusion of the maxillary incisors. ${ }^{8}$

Bone malformations may also result from the duration and frequency of harmful habits. ${ }^{5}$ Hence these habits, when excessive or are continued past appropriate developmental necessity, can lead to poor dental health, be socially stigmatizing, and inhibit the development of speech clarity. Therefore, habits require a multidisciplinary approach to provide integral care to child patients.

The prevalence of oral habits in school children has not been clearly documented in different population groups across Egypt. Hence an attempt has been made to study the prevalence of oral habits in children of 6-12 years old age group in Dakahlya governorate, Egypt . The knowledge of the school children of this age regarding the bad effect of practicing these habits on their oral health has also been clarified.

\section{MATERIALS AND METHODS}

A total of 2274 children,1106 males and 1168 females were randomly selected according to multistage stratified cluster sampling design. The study target population consisted of children between 6-12 years of age who were attending public schools in Dakahlya province during the school year 2013-2014, in both rural and urban areas. Fifteen examined schools, ten in the town and five in the rural areas were chosen.

The study group was further subdivided into two age groups. Group1 (6-<9 years ) and Group 2 (912 years ).The study was approved by Mansoura university ethics committee. Survey was conducted in two steps, which included clinical examination to elucidate signs of oral habits followed by interviewing questionnaire. Prevalence rates of different oral habits studied were calculated. Moreover, a question regarding the students' knowledge about the harmful effect of performing oral habit on their oral health is also included 
The sample inclusion criteria were:

- The parents had given consent

- The behavior of the child was adequate for the purposes of examination.

- Systemically free children

The sample exclusion criteria:

- Children with craniofacial anomalies syndrome

- Children having received or currently receiving any type of orthodontic treatment with the exception of space maintainer.

The examination of the children was performed by the two calibrated examiners. To ensure intraand inter-examiner reliability, the examiners examined 30 children on two occasions at least one week apart. The results obtained were almost the same for all parameters (Kappa Value for inter and intra-examiner variability were 0.95 and 0.89 respectively). It was conducted on the medical examination room of the school at up-right chair using disposable latex glove, disposable mouth mirror and probe and torch light.

Chi-square test at 5\% level of significance was used to compare the prevalence of oral habits and the children knowledge among different sexes and ages.

\section{RESULTS}

A total of 2,274 subjects, 1,106 males (48.6\%) and 1,168 females (51.4\%) 6-12 years old school children, were examined as shown in (Table 1).

TABLE (1) Distribution of the sample according to age and sex.

\begin{tabular}{|c|c|c|c|}
\hline Age group & \multicolumn{2}{|c|}{ Sex } & Total sample \\
\hline & Male & Female & \\
\hline Group1( 6-<9 years) & 550 & 588 & 1138 \\
\hline Group 2 (9-12years) & 556 & 580 & 1136 \\
\hline Total & 1106 & 1168 & 2274 \\
\hline
\end{tabular}

The results showed that the prevalence of oral habits in Dakahlya school children was $29.1 \%$. Nail biting was the commonest habit $(9.7 \%)$ followed by digit sucking $(6.1 \%)$, mouth breathing $(4.6 \%)$, tongue thrusting(3.4\%), bruxism(3.1\%). Lip/cheek biting was relatively the least common habit and recorded in only $2.2 \%$ of children.

According to both age groups. Digit sucking, mouth breathing and tongue thrusting were prevalent among Group1 (6-<9 years) children. However, nail biting was highly prevalent in Group 2 (9-12 years) children followed by bruxism and Lip/cheek biting. No statistical significant differences between the two age groups as shown in (Table2).

TABLE (2) The prevalence of different oral habits among both age groups

\begin{tabular}{|l|c|c|c|c|c|c|c|}
\hline \multirow{2}{*}{ Habit } & \multicolumn{2}{|c|}{$\begin{array}{c}6-<9 \\
\mathrm{~N}=1138\end{array}$} & \multicolumn{2}{c|}{$\begin{array}{c}\text { 9-12years } \\
\mathrm{N}=1136\end{array}$} & \multicolumn{2}{c|}{$\begin{array}{c}\text { Total sample } \\
\mathrm{N}=2274\end{array}$} & \multirow{2}{*}{ P value } \\
\cline { 2 - 8 } & $\mathrm{N}$ & $\%$ & $\mathrm{~N}$ & $\%$ & $\mathrm{n}$ & $\%$ & \\
\hline Digit sucking & 98 & 8.6 & 41 & 3.6 & 139 & 6.1 & 0.165 \\
\hline Mouth breathing & 54 & 4.7 & 51 & 4.4 & 105 & 4.6 & 0.924 \\
\hline Tongue thrust & 60 & 5.3 & 12 & 1.1 & 72 & 3.4 & 0.102 \\
\hline Bruxism & 35 & 3.1 & 39 & 3.3 & 74 & 3.1 & 0.938 \\
\hline Lip/cheek biting & 19 & 1.7 & 31 & 2.7 & 50 & 2.2 & 0.638 \\
\hline Nail biting & 71 & 6.1 & 151 & 13.2 & 222 & 9.7 & 0.123 \\
\hline Total & 337 & 29.6 & 325 & 28.6 & 662 & 29.1 & 0.909 \\
\hline
\end{tabular}

*Significant at $5 \%$ level $(\mathrm{p}<5 \%)$ 
According to gender, there were no statistical significant differences between males and females for the prevalence of oral habits (26\%vs 32\%). However, for the specific habit type there was a sex difference. Tongue thrust was more common in males $(5 \%)$ when compared with females $(1.5 \%)$ with statistical significant difference $(\mathrm{P}<5 \%)$. Nail biting were highly prevalent among females and this difference was statistically significant $(\mathrm{P}$ $<0.05)$. There was a reverse trend for the mouth breathing, and bruxism, which were more common in males $(6.5 \%$, and $5.4 \%)$ than girls $(2.8 \%$,and $1.2 \%)$ respectively with no statistical significant differences as shown in (Table 3).
Children knowledge regarding the effect of oral habits on their oral health is depicted in table 4. Results showed that, $46.83 \%$ of children were found to be aware by the ill effect of oral habits on their oral health, while $53.17 \%$ were not. Girls were found to be more oriented by the ill effect of practicing oral habits on their oral health than boys with no statistical significant difference. On the other hand, statistically significant differences were found between the two age groups with older age group (9-12) year's old showing higher awareness.

TABLE (3) Prevalence of oral habits according to gender

\begin{tabular}{|l|c|c|c|c|c|c|c|}
\hline \multirow{2}{*}{ Habit } & \multicolumn{2}{|c|}{$\begin{array}{c}\text { Male } \\
\mathrm{N}=1106\end{array}$} & \multicolumn{2}{c|}{$\begin{array}{c}\text { Female } \\
\mathrm{N}=1168\end{array}$} & \multicolumn{2}{c|}{$\begin{array}{c}\text { Total sample } \\
\mathrm{N}=2274\end{array}$} & \multirow{2}{*}{$\mathrm{P}$ value } \\
\cline { 2 - 8 } & $\mathrm{N}$ & $\%$ & $\mathrm{~N}$ & $\%$ & $\mathrm{~N}$ & $\%$ & $\mathrm{P}=0.25$ \\
\hline Digit sucking & 44 & 4 & 95 & 8.1 & 139 & 6.1 & $\mathrm{P}=0.24$ \\
\hline Mouth breathing & 72 & 6.5 & 33 & 2.8 & 105 & 4.6 & $\mathrm{P}=0.03 *$ \\
\hline Tongue thrust & 55 & 5 & 17 & 1.5 & 72 & 3.4 & $\mathrm{P}=0.13$ \\
\hline Bruxism & 60 & 5.4 & 14 & 1.2 & 74 & 3.1 & $\mathrm{P}=0.3$ \\
\hline Lip /cheekbiting & 12 & 1.1 & 38 & 3.3 & 50 & 2.2 & $\mathrm{P}=0.02 *$ \\
\hline Nail biting & 45 & 4.1 & 177 & 15.1 & 222 & 9.7 & $\mathrm{P}=0.49$ \\
\hline Total & 288 & 26 & 374 & 32 & 662 & 29.1 & \\
\hline
\end{tabular}

*Statistically significant difference $(P<5 \%)$.

TABLE (4) Children knowledge regarding the bad effect of oral habits on their oral health.

\begin{tabular}{|c|c|c|c|c|c|c|c|c|c|c|}
\hline & \multicolumn{2}{|c|}{$\begin{array}{c}6->9 \text { years } \\
N=337\end{array}$} & \multicolumn{2}{|c|}{$\begin{array}{c}9-12 \text { years } \\
\mathrm{N}=325\end{array}$} & \multirow{2}{*}{$\mathrm{P}$ value } & \multicolumn{2}{|c|}{$\begin{array}{c}\text { Male } \\
\mathrm{N}=288\end{array}$} & \multicolumn{2}{|c|}{$\begin{array}{l}\text { Female } \\
\mathrm{N}=374\end{array}$} & \multirow{2}{*}{$\mathrm{P}$ value } \\
\hline & $\mathrm{N}$ & $\%$ & $\mathrm{~N}$ & $\%$ & & $\mathrm{~N}$ & $\%$ & $\mathrm{~N}$ & $\%$ & \\
\hline There is effect on oral health & 112 & 33.2 & 198 & 60.9 & $0.018^{*}$ & 128 & 44.4 & 182 & 48.7 & $\mathrm{P}=0.712$ \\
\hline No effect on oral health & 225 & 66.8 & 127 & 39.1 & $0.029 *$ & 160 & 55.6 & 192 & 51.3 & $\mathrm{P}=0.737$ \\
\hline Total & 337 & 100 & 325 & 100 & & 288 & 100 & 374 & 100 & \\
\hline
\end{tabular}

*Statistically significant difference $(P<5 \%)$. 


\section{DISCUSSION}

This research on Dakahlya governorate which lies at the north east of Egypt may serve as a preliminary data for further planning on oral health development, especially in preventing oral habits in primary school children. This may later increase the level of oral health in Egypt. Action defined as oral habits in this study are digit sucking, lip/cheek sucking orbiting, tongue thrusting, nail biting and mouth breathing.

The present study results showed that $29.1 \%$ of primary school children in Dakahlya province practiced oral habits. Although both sex types have equal risks in practicing oral habits, female children showed a greater prevalence rate of oral habits than males with no statistical significant difference (26\%vs $32 \%$ ) as shown in table 3.

This finding is quite comparable to the data reported in other surveys of Shetty et al, ${ }^{9}$ and Kharbanda et al, ${ }^{10}$ who reported prevalence of oral habits $(29.7 \%$ \& $25.5 \%)$ in south and north Indian children respectively. In contrast to this observation, high prevalence of oral habits was reported by Quashie-Williams ${ }^{11}$, and DP Bahaya ${ }^{12}$ who found $34.1 \%$ and $38 \%$ of the children examined presented with an oral habit. Higher prevalence $(50 \%, 51.1 \%, 71.1 \%$ and $80.6 \%)$ of oral habits had been reported by,Geldasya , Garde ,Leme et al \& Lagana et ${ }^{13-16}$.On the other hand, Lower prevalence was recorded by Hegde and Almonaitienè et al 17,18 who reported $(19.95 \& 19.7 \%)$ children practicing oral habits. Further, Guba et al., ${ }^{19}$ reported that only $3 \%$ of children demonstrated oral habits, which is very much in disagreement with the present findings.

The present study showed that female children were exhibited more oral habits than males (32\% Vs $26 \%$ ) with no statistical significant difference which is running with several previous studies 12,14,16-18. The reason behind the gender wise difference may be due to the fact that oral habits in girls are more common due to hormonal changes and diet. ${ }^{14}$
In contrast to this observation, sexual variation with a higher prevalence in males was reported by others ${ }^{11-13}$. They explained their results by the tendency of boys to openly fight against family's or surrounding society's rules than girls. To date, there is no consensus regarding the prevalence of oral habits and their association with gender. The lack of consensus might be explained by the different dentition stages of the evaluated populations. ${ }^{15}$

Although the prevalence rates of oral habits reported in literature have been widely divergent, most researches ${ }^{15-18}$ agree with the results of the present study that both digit sucking and nail biting are the most frequent ones present during childhood. On the other hands, tongue thrusting and mouth breathing were reported as the most prevalent practicing habits by other researchers. ${ }^{10,12,19}$

Whereas digit sucking was the most frequently occurring oral habits seen in $50 \%$ of the children in the reports of Quashie-Williams et al. ${ }^{11}$, present study revealed that nail biting habit was the most prevalent oral habit in $9.7 \%$ of children. This observation is in disagreement with the finding of Shetty and Munshi ${ }^{9}$ who reported $12.7 \%$ of children with nail biting, while a very low incidence(3\%) was reported by Bahaya and Shygali. ${ }^{12}$

Mouth breathing habit was the third most prevalent habit in the present study with the incident rate of $4.6 \%$. This incidence was in complete consensus with Shetty and Munshi ${ }^{9}$ result, but lower when compared to the findings of Kharabanda et al ${ }^{10}$ and Bahaya and Shyagali ${ }^{12}$ who reported mouth breathing habit in $6.6 \%$ and $17 \%$ of children.

Current study recorded tongue thrusting habit as the forth prevalent habit among 3.4\% of children. This finding agreed with the findings of Shetty and Munshi ${ }^{9}$ who found a comparatively low prevalence (3.02\%) of tongue thrusting habit among Mangalore children in the age range of 3-16 years. However, it differed with the findings of Kharbanda et al ${ }^{10}$ and Bahaya and Shayagali ${ }^{12}$ who observed tongue thrusting habit in $18 \%$ and $18.1 \%$ of children. 
Although, Bruxism and lip biting habits were absent in Bahaya and Shygali study group, present study reported these two habits as the least common habits with incident rate of $(3.1 \% \& 2.2 \%)$ respectively. However, the previous literature on the oral habits suggested higher prevalence of them. ${ }^{9-11}$

Regarding findings on nail biting in the current study, the habit was found to be more prevalent $(13.2 \%)$ in older age groups (9-12) years old and actually preceded digit sucking. But still the prevalence of nail biting was higher in the present study children $(9.7 \%)$ as shown in table 2 if compared to the published studies of Almonaitiene et al ${ }^{18} 7.9 \%$ and Bahaya ${ }^{12} 3 \%$. On the other hand, the present result reported a lower rate compared to the results of Quashie ${ }^{23} \% 11$ and shety ${ }^{9} 12.7 \%$. One of reason could lay in the study design, as the age of children in this study included children up to the age of twelve years, while others included children up to the age of fifteen. It is well documented that the incidence of nail biting increases considerably during adolescence ${ }^{20}$. The etiology of nail biting is considered as mainly emotional arising from anxiety, nervousness, tension and familial transmission ${ }^{20-22}$

Although bruxism was reported more often than the lip/cheek biting in the present study, the incidence of the later was more variable while the former one was more stable if age groups are taken into account as shown in table 2. In agreement with previous study results, ${ }^{18}$ the high incidence of lip biting $2.7 \%$ in (9-12) years old group could be explained in the light of stress acting as the main etiological factor, as children attend school at this age. In comparison, study on Saudi Arabian children found the prevalence of cheek biting to be $4 \%$ in primary dentition and $15 \%$ in mixed dentition $^{23}$. The reasons for differences between current study and published one could be attributed to the different study methodology (self report Vs parent report, different age of children and different cultures).
Adverse oral habits may produce harmful effects on the development of maxillofacial complex..$^{24-26}$

The knowledge of children in the present study revealed that $53.17 \%$ were not aware by the harmful effect of practicing oral habits on their oral health. This result was lower than other population depicting a high percentage of $77 \%$ children unaware of the ill effects of oral habits ${ }^{17}$. Running with previous studies, ${ }^{27,28}$ sexual variation appears with a higher awareness among females with no statistical significant difference as shown in table 4 is justifiable. Teeth appearance was important for girls and had a high impact on their appearance satisfaction. ${ }^{27}$

Knowledge of the children in the current study regarding the ill effect of oral habits on oral health showed age differences. Older age group (912) years old reported a higher rate of awareness $(60.9 \%)$ in comparison to $(39.1 \%)$ in young age group (6-<9) years old. This difference was found to be statistically significant $(\mathrm{P}<5 \%)$ as shown in table 4 .

Although there are some short comings of this study, including children-based questionnaires about events some years ago, but it is definitely important in gaining data on the type and prevalence of oral habits among school age children in Dakahlya governorate , Egypt. It also expands the knowledge of children regarding oral habits practicing effects on their oral health.

\section{CONCLUSIONS}

1- The prevalence of oral habit type differs with age: Digit sucking was more prevalent in younger children while nail biting-in older one.

2- No significant difference has been found between genders in the prevalence of oral habits. However, for the specific habit type, there was a sex difference.

3- $53.17 \%$ of children were unaware of the potential hazards that the adverse oral habit could pose on one's oral health. 


\section{REFERENCES}

1. World Health Organization. Health Promotion Glossary [Internet]. Geneva: World Health Organization;1986. [2012 Oct 15].

2. Petersen PE. The World Oral Health report : continuous improvement of oral health in the 21st century - the approach of the WHO Global Oral Health Program. Community Dent Oral Epidemiol 2003 Dec; 31Suppl.1:3-24.

3. AM Piteo, JD Kennedy, RM Roberts, AJ Martin, T Nettelbeck, MJ Kohler, al et. Snoring and cognitive development in infancy. Sleep Med. 2011;12:981-987.

4. JA Maguire. The evaluation and treatment of pediatric oral habits. Dent Clin North Am. 2000;44:659-669

5. PV Agurto, RM Diaz, OD Cadiz, FK Bobenrieth. Oral bad habits frequency and its association with dentomaxilar abnormal development, in children three to six year old in Santiago Oriente. Rev Chil Pediatr.1999;70:470-482.

6. LD Vogel. When children put their fingers in their mouths. Should parents and dentists care? N Y State Dent J. 1998;64(2):48-53.

7. A Monaco, NM Ciammella, MC Marci, R Pirro, M Giannoni. The anxiety in bruxer child: A casecontrol study. Minerva Stomatol. 2002;51(6):247-250.

8. JA Dean, RE McDonald, DA Avery. Managing the developing occlusion. St. Louis, Mo:CV Mosby and Co. 2000:178-217.

9. SR Shetty, AK Munshi. Oral habits in children: a prevalence study. J Indian Soc Pedod Prev Dent.1998;17(2):61-66

10. OP Kharbanda, SS Sidhu, KR Sundaram, DK Shukla. Oral habits in school going children of Delhi: a prevalence study. J Indian Soc Pedo Prev Dent. 2003;21(3):120-124.

11. R Quashie-Williams, OO Dacosta, MC Isiekwe. The prevalence of oral habits among 4 to 15 year old school children in Lagos. Niger $\mathrm{J}$ Health Biomed Sci. 2007;6(1):78-82.

12. DP Bhayya, TR Shyagali. Prevalence of oral Habits in 1113 year-old School Children in Gulbarga city, India. Virtual J Orthod. 2009;8(3):1-4.

13. E Gildasya, H Syarief. Prevalence of oral habits in homeless children under care of Yayasan Bahtera Bandung. Dent J. 2006;39(4):165-167.

14. Garde J B, Suryavanshi RK, Jawale BA, Deshmukh V, Dadhe D and Suryavanshi MK. An epidemiological study to know the prevalence of deleterious oral habits among 6 to 12 year old children. J Int Oral Health. Feb 2014; 6(1): $39-43$

15. Marina S L, Taís de Souza Barbosa, Maria Beatriz Duarte Gavião. Relationship among oral habits, orofacial function and oral health-related quality of life in children. Braz. oral res. vol.27 no.3 São Paulo May/June 2013

16. Lagana G, Masucci C, Fabi F,Bollero P and Cozza P. Prevalence of malocclusions, oral habits and orthodontic treatment need in 7 to 15 years old children population in Tirana. Progress in orthodontics, 14:12,2013.

17. Amitha M Hegde, 2Arun M Xavier Childhood Habits: Ignorance is not Bliss-A Prevalence Study. International Journal of Clinical Pediatric Dentistry, January-April 2009;2(1):26-29

18. Almonaitiene R, Balciuniene I, Tutkuviene J.Prevalence of oral habits and their impacts on facial parameters in Lithuanian children 4 to 9 years of age. teorija ir praktika 2013 - T. 19 (Nr. 1), 31-38 p

19. Guaba K,Ashima G, Tewati A, Utreja A. Prevalence of malocclusion and abnormal habits in North Indian rural children. J Ind Soc of Pedo Prev Dent,16:26-30,1998.

20. Tanaka OM, Vitral RWF, Tanaka GY, Guerrero AP, Camargo ES. Nailbiting, or onychophagia: A special habit. American Journal of Orthodontics and Dentofacial Orthopedics 2008; 134: 305-308.

21. Bosnjak A, Vucicevic-Boras V, Miletic I, Bozic D, Vukelja M. Incidence of oral habits in children with mixed dentition. J Oral Rehabil 2002; 29: 902-905.

22. Ooki S. Genetic and environmental influences on fingersucking and nail-biting in Japanese twin children. Twin Res Hum Genet 2005; 8: 320-327

23. Farsi NM. Symptoms and signs of temporomandibular disorders and oral parafunctions among Saudi children. J Oral Rehabil 2003; 30: 1200-1208.

24. Oral Health Policies. Policy on Oral habits. American Academyof Pediatric Dentistry. Refernce Manual 07/08; 29(7):49-50.

25. Paola C, Tiziano B, et al. Sucking habits and facial hyperdivergency as risk factors for anterior open bite in the mixed dentition. Am J Orthod Dentofacial Orthop 2005;128(4):517-9.

26. Cozza P, Tiziano B. Transverse features of subjects with sucking habits and facial hyperdivergency in the mixed dentition. Am J Orthod Dentofacial Orthop 2007;132:226-9.

27. Peres KG, Barros AJD, Anselmi L, Peres MA, Barros FC. Does malocclusion influence the adolescent's satisfaction with appearance? A cross-sectional study nested in a Brazilian birth cohort. Community Dent Oral Epidemiol. 2008 Apr; 36(2):137-43.

28. Barbosa TS, Tureli MCM, Gavião MBD. Validity and reliability of the child perceptions questionnaires applied in Brazilian children. BMC Oral Health. 2009 May;18:913 doi: 10.1186/1472-6831-9-13. 